\title{
How social influences and work environment affect the overall experience of tefl teachers in China
}

Gabriella Berman*† https://orcid.org/0000-0003-3010-6722

Adele Potgieter ${ }^{* *}$ https://orcid.org/0000-0002-2495-3821

*Nelson Mandela University, Port Elizabeth, South Africa. Email: s215032950@mandela.ac.za

** Nelson Mandela University, George, South Africa. Email: adele.potgieter@mandela.ac.za

Abstract

Background. Expatriation has grown rapidly, and the TEFL (teaching English as a foreign language) industry relies on it heavily. As is the case with any expatriation adjustment, TEFL teachers'overall experience of living and working in China can be influenced by external factors. For the purpose of the study described in this article, both social influences and the work environment are highlighted as influences on the overall experience of teaching TEFL in China.

Research aims: The research aim of the study was to investigate the effect of social influences and work environment on the overall experience of TEFL teachers who teach in China.

Methodology. The study made use of a positivistic research paradigm and a descriptive research design. The sampling procedure utilised in the study was non-probability sampling, and the technique used was convenience sampling. The target population comprised TEFL teachers who were teaching in China, with the final sample consisting of 379 respondents. To collect data, the method used was an online survey, and the specific measuring instrument was a web-based, self-administered questionnaire, distributed via a link on Facebook, WeChat, LinkedIn, and Reddit groups that are specifically for TEFL teachers in China. Once the data were collected, both descriptive and inferential statistics were utilised to analyse and interpret the data.

Findings. From the empirical data collected in the study, it was found that, in general, both social influences and the work environment of TEFL teachers in China positively affected their overall experience, while the potential influence of a language barrier proved to have no negative effect on their overall experience.

Keywords

social influences, work environment, TEFL teaching, China, experience

\section{INTRODUCTION}

Traditionally, the term "expatriate" was used to define individuals deployed to another country by their hiring company to work for a predefined amount of time (Holland, 2019; Ročkè, 2017). However, in recent literature, the term has been used more broadly to describe individuals who live in a country to which they are not native (McNulty \& Brewster, 2017a), including those who engage in both work-related and non-work-related, international experiences (McNulty \& Brewster, 2017b). According to Bonache et al. (2017), expatriation is not a new concept. However, due to globalisation, there has been a distinct rise in the number of expatriates worldwide (Massey, 2016). One industry that relies heavily on expatriates is the TEFL (teaching English as a foreign language) industry.

\section{BACKGROUND}

Yim and Ahn (2018) define TEFL in terms of a native English-speaking individual teaching the English language to a non-native English speaker. The TEFL industry is growing rapidly, and in 2020 had an estimated market value of $\$ 200$ billion (The TEFL Academy, 2020), with approximately 500,000 foreign TEFL teachers in China alone (Maxwell, 2019; Quinn, 2019).

With specific reference to China, there are certain requirements for working as a TEFL teacher. The applicant must be a fluent English speaker (i-to-I, 2020); have a 120+ hour TEFL certification, or some variation thereof (i-to-I, 2020); have a clear national

${ }^{+}$Corresponding author 
criminal background check and a clean bill of health from a licensed doctor (Reach to Teach, 2020); and hold a bachelor's degree in any field (Taleb-Agha, 2020). Additionally, while not a requirement, it is preferred for the applicant to be of a younger age (20s to 30s) (The International TEFL Academy, 2020).

As is the case with any form of expatriation, the process of expatriation for TEFL teachers in China is littered with challenges (Ročke; 2017). Challenges associated with expatriation encompass both work and personal adaptation (Ročke;, 2017), such as culture shock, work norms, missing home, healthcare systems, and language barriers. When considering TEFL teaching in China, a number of factors have been identified that have a notable influence on the overall experience of a TEFL teacher. These include the presence of an expatriation community (Hello Teacher, 2020; OpportunityChina, 2020); the potential influence of a language barrier (OpportunityChina, 2020); acceptance by locals (OpportunityChina, 2020); access to healthcare (Osborne, 2020); work conditions (King, 2018); and working hours (Hello Teacher, 2020). For the purpose of the study, these factors were grouped to form two variables that were named "social influences" and "work environment."

\section{Social Influences}

Settersten and Thogmartin (2018) argue that all experiences should be viewed as interpersonal, as experiences usually involve other people. Moreover, it should be noted that social determinants can have a positive or negative effect on a specific experience and can have an overall effect on an individual's lifestyle (GPI, 2016). Geher et al. (2020) maintain that the social sphere of an individual's life should be considered as a highly important influence on his/her mental and physical health. From the literature on social influences, the following hypothesis was derived.

$H_{1} \quad$ There is a significant relationship between social influences and the overall experience of foreign TEFL teachers who teach in China.

\section{The presence of an expatriate community}

DeVries (2017) explains that expatriates are known to form social bonds, attributed to the similarities in their situations. Ultimately these become "expat communities" (InterNations, 2020), which have been known to make the transition into a new country easier (Schmidt, 2019; Van der Laken et al., 2019). Rousseau (2020) claims that it is important for expatriates to practice traditions from their home country as this can ease the effects of culture shock and therefore contribute to a smooth transitioning into a new country. Rousseau (2020) adds that the physical celebration of a traditional day can increase the ability of expatriates to connect with fellow expatriates from their home countries, which contributes to a mutual support system. From the literature on the presence of an expatriate community, the following hypothesis was derived.

\section{$H_{1 a} \quad$ There is a significant relationship between the presence of an expatriate community and the overall experience of foreign TEFL teachers who teach in China.}

\section{The potential influence of a language barrier}

A language barrier, as explained by Rani (2016), is a form of communication barrier that prevents the successful translation and understanding of information, ideas, and thoughts. Ching et al. (2017) and Zhang et al. (2017) emphasise that language barriers can present a challenge to transitioning into a new country. This is because language barriers have been found to give rise to feelings of anxiety, loneliness, confusion, and frustration (Chiona, 2017; Tenzer \& Schuster, 2017).

Tenzer and Schuster (2017) are of the opinion that the influence of business language in a workplace can either hinder or facilitate the success of an expatriate. The influence of business language can be attributed to the fact that interpersonal relationships, individual adjustment, and group dynamics are all dependent on the ability to communicate. Furthermore, Tenzer and Schuster (2017) note that employees, both expatriate as well as host nationals, can have emotional reactions to language diversity in the workplace. An example of this is the expatriates' fear of being viewed negatively or shown a lack of respect by host national co-workers due to their inability to speak the home language of the country of employment (Tenzer \& Schuster, 2017; Zhang \& Harzing, 2016). Furthermore, it has been observed that expatriates often show a resistance to learning the language of their host country (Zhang \& Harzing, 2016), which Kolakowski (2018) as well as Soler and Marten (2019) link to the difficulty involved in learning languages. However, Mandarin and Chinese languages, in particular, have recently started to grow in popularity (Costa 2018), with many schools in America offering Mandarin and Chinese languages as a second language subject (Wang Ying, 2017). Makovsky (2014) along with Pogosyan (2017) concur that the learning of nuances and non-verbal cues associated with language are even more confusing, which can lead to misunderstanding due to cultural biases. 
Drucker (2017) observes that non-verbal communication accounts for half of the information conveyed through a conversation. In addition, it determines the way in which individuals send and receive information beyond words. In order to try to alleviate the language barriers for TEFL teachers, many employers include language lessons in their employment contracts for expatriate employees (Mitchell, 2019) to foster acceptance by locals. Zhang and Harzing (2016) claim that as it can take a long time to learn a language, long-term expatriates are more likely to learn the home language of the country they work in. From the literature on the potential influence of a language barrier, the following hypothesis was derived.

\section{$H_{1 b} \quad$ There is a significant relationship between the potential influence of a language barrier and the overall} experience of foreign TEFL teachers who teach in China.

\section{Acceptance by locals}

Personal encounters involving interaction between locals and expatriates can have an impact on the attitudes and satisfaction of both parties (Carneiro \& Eusébio, 2015). Hunt (2018) as well as Zhang et al. (2017) support Carneiro and Eusébio (2015) in maintaining that residents of a country are often of the opinion that expatriates disrupt their culture, heritage, and general day-to-day lives. Okulicz-Kozaryn and Strzelecka (2017) point out that the relationship between locals and expatriates is fragile because the negative repercussions of expatriates' presence are considered to be high by locals, even though economic growth is appreciated. The overall experience of individuals working abroad is influenced by the degree of acceptance of expatriates by locals in the host country (OpportunityChina, 2020). However, Galloway (2019) maintains that when expatriates are respectful of the local culture and heritage residents are more inclined to be accepting of them. Sokro and Pillay (2020) agree with Galloway (2019) and add that if host national workers have positive attitudes toward expatriate co-workers and are willing to support them, then expatriates are more likely to succeed in their careers.

As indicated by Sokro and Pillay (2020), relationships between expatriates and locals both inside and outside of the workplace are important, which Mahajan and Toh (2014) attribute to the relationships' ability to ease the transition of expatriates into a new country. Sokro and Pillay (2020) add to the debate and state that in-depth knowledge passed from a host national co-worker to an expatriate about the country and company culture can assist in expatriate adjustment. Solomon (2019) adds that adjustment to a new country can take time, and the period of adjustment will influence the expatriate's experience of working abroad.

The dislike shown by locals of a country toward foreigners is known as "xenophobia," which Masenya (2017) maintains is more than just dislike and, in fact, encompasses the attitudes, prejudices, and behaviour of locals who reject and disparage foreigners. Xenophobia is often manifested in the form of discriminatory behaviour, violence, and abuse. Moreover, it is rooted in locals' feelings of superiority, lack of intercultural understanding, and the notion that foreigners impose a threat to locals in some way (Masenya, 2017). Therefore, xenophobia can have an impact on the expatriate's experience in a foreign country. Furthermore, as explained by Kuo and Davidson (2020), due to the COVID-19 pandemic, the attitudes of host nationals in China are changing and have become less welcoming toward foreigners. From the literature on the acceptance of expatriates by locals, the following hypothesis was derived.

$H_{1 c} \quad$ There is a significant relationship between acceptance by locals and the overall experience of foreign TEFL teachers who teach in China.

\section{Access to healthcare}

Healthcare can have an impact on an individual's physical, mental, emotional, and social well-being (Foundation Health Measure Report, 2020). Moopen (2020) explains that ideally, healthcare should be accessible, affordable, and of an acceptable quality to have a positive impact on an individual's well-being. Mogawakwe et al. (2020) as well as Moopen (2020) explain that facilities provided are often of a poor quality and are understaffed due to a lack of budget and resources, with many people having to travel far to access healthcare, which is the case in developing countries (Guettou, 2018).

Furthermore, in China specifically, healthcare can be very expensive (Pacific Prime China, 2018), and there is a difference between rural and urban facilities (Spasojevic et al., 2015). In an attempt to meet the healthcare needs of expatriate workers, who would otherwise be left without access to medical services, employers often include medical insurance in work contracts, such as those signed by TEFL teachers (Deady, 2018). From the literature on expatriate access to healthcare, the following hypothesis was derived.

$H_{1 d} \quad$ There is a significant relationship between access to healthcare and the overall experience of foreign TEFL teachers who teach in China. 


\section{Work Environment}

A work environment has been defined by Kitila (2017) as the physical, inter-relational and complete setting in which an individual works. Kitila (2017) as well as Oludeyi (2015) maintain that an individual's work environment can influence his/ her job satisfaction and productivity. Additionally, Kitila (2017) posits that a good work environment can influence not only the performance, but also the behavior and attitude of an individual. Zafar et al. (2017) agree with Kitila (2017) and report that the work environment can enhance an individual's intrinsic and extrinsic needs. From the literature on work environment, the following hypothesis was derived.

\section{$\mathrm{H}_{2} \quad$ There is a significant relationship between work environment and the overall experience of foreign TEFL} teachers who teach in China.

\section{Work conditions}

Working conditions are essential to any employment contract covering aspects such as the physical work conditions within the workplace and the mental demands associated with the work (The International Labour Organisation, 2020). As explained by Kelly (2019), in the teaching industry there are two distinguishable sectors, namely the private and public sector, which are notably different, each suiting different people. Both King (2018) and York (2019) insist that TEFL teachers' work environment and overall experience in China will vary depending on whether they work in a private or public school.

It is accepted that private teaching institutions have smaller class sizes than those of public teaching institutions, allowing private-school teachers to interact in a more task-orientated manner and to build relationships with each individual student (Grossberg 2019; Mathis 2017). Mueller (2013), Mayes-Tang (2017), and Jokhio et al. (2020) claim that in larger classes, the teacher may face challenges, such as work overload, that make it impossible to provide sufficient feedback to learners. Other challenges include not having time to ensure that all students participate; dealing with a high noise level; engaging with students who have mixed abilities; and not being able to develop relationships with each student, as is possible in smaller class. In China, the roles and responsibilities of teachers in private schools differ from those in public schools. Tingley (2020) and York (2019) explain that in a private institution, the students are seen as clients, as school funding relies on student retention. Therefore, it is considered the responsibility of the teacher to create a balance between placing pressure on students to excel and ensuring students do not leave. Meador (2019) and Tingley (2020) maintain that beyond encouraging students to continue their academic journey with the school, it is the private school teacher's role to concern him/herself with the school budget, which can include taking part in after-hours events, such as pledges, dinners, auctions, and other fundraisers. From the literature on work conditions, the following hypothesis was derived.

\section{$H_{2 a} \quad$ There is a significant relationship between work conditions and the overall experience of foreign TEFL teachers who teach in China.}

\section{Working hours}

Collewet and Sauermann (2017) observe that due to countries having different labour laws concerning working hours, an individual can expect to work very different hours from country to country, and even from job to job. Agboza, Owusu, Hoedoafia and Atakorah (2017), Collewet and Sauermann (2017) as well as Okazaki, et al. (2018) all agree that working hours are related to employee productivity and satisfaction. The working hours of TEFL teachers differ depending on the school, teaching schedule, and type of institution. However, in most cases, the general norm is a \pm 40 -hour workweek (Mitchell, 2019). The \pm 40 -hour workweek week comprises \pm 25 hours of contact teaching time per week, during which teachers interact with students in a classroom environment (Bridge TEFL, 2020), 2.5 to 3 hours of free time, such as for lunch or children's nap time, and \pm 12 hours of administration work (Mitchell, 2019).

The choice of whether to work in a private or public teaching institution is based on the preference of each individual TEFL teacher. In fact, according to Lee and Lim (2017), a change in working hours can either cause workers to feel fatigued or increase their productivity. From the literature on working hours, the following hypothesis was derived.

$H_{2 b} \quad$ There is a significant relationship between working hours and the overall experience of foreign TEFL teachers who teach in China. 


\section{METHOD}

The study made use of a positivistic research paradigm, a descriptive research design, and non-probability sampling, more specifically, convenience sampling. The target population included TEFL teachers who were teaching in China, with the final sample consisting of 379 TEFL teacher respondents (response rate of $80.2 \%$ ). The data collection method used was an online survey, and the specific measuring instrument was a web-based, self-administered questionnaire, consisting of four sections, namely Section A: Demographics; Section B: Social influences; Section C: Work environment; and Section D: Overall experience. The primary data for this study were collected in August 2020 and September 2020, which was during the time of the global COVID-19 pandemic, via 5-point Likert-scale questions. For reporting purposes, responses of 4 (positive) and 5 (very positive) were grouped as a positive overall influence, whereas responses of 2 (negative) and 1 (very negative) were grouped as a negative overall experience.

A link to the questionnaire was posted on social media platforms (Facebook, WeChat, Linkedln, and Reddit groups) that are specifically for TEFL teachers in China. The data collected in this study were edited and coded in an Excel spreadsheet. Using STATISTICA, both descriptive and inferential statistics were calculated and then analysed/interpreted. To determine if statistically significant differences in opinions occurred, ANOVA was conducted, and where a significant difference was identified, Tukey's test for post hoc analysis was conducted to identify specifically where the significant difference $(p<0.05$ or $p<0.10$ ) occurred.

The study made use of exploratory factor analysis (EFA) to ensure the construct validity of the questionnaire, whereas content validity was addressed by using of previously tested items in the questionnaire. The EFA revealed that two items within the variable "social influences" had to be deleted, and one item had to be deleted within the variable "work environment."

The data was subjected to factor analysis using principal axis factoring and the Oblimin, with the Kaiser normalisation variation method (KMO) being utilised. The KMO values for both social influences (0.881) and work environment (0.907) were above 0.7 (Nunnally \& Bernstein, 1994), indicating that the data were sufficient for EFA. Through the use of Eigenvalues cut-off of 1.0 (Kaiser, 1960), the total amount of factors that cumulatively contributed to at least $50 \%$ of the cumulative variance were identified. Using the eigenvalue cut-off of 1.0, four factors, namely expatriate community, language barrier, acceptance by locals, and access to healthcare, explained a cumulative variance of $56.14 \%$ of the variable "social influences." Within the variable "work environment," two factors, namely "work conditions" and "working hours," explained a cumulative variance of $58.42 \%$. Once the EFA had been conducted, Cronbach's alpha coefficients were calculated for each of the remaining variables to measure their reliability.

The variables constituting the variable "social influences" presented Cronbach's alpha values ranging from $0.81-0.83$ and an average inter-item correlation ranging from $0.46-0.54$, indicating that there was consistency in the values. The variables constituting the variable "work environment" presented Cronbach's alpha values ranging from 0.77 to 0.85 and average interitem correlations ranging from 0.41 to 0.54 , indicating that there was consistency in the values. All the Cronbach's alpha values calculated for the variables and sub-variables of the study were above the suggested 0.7 cut-off value proposed by Nunnally (1978); therefore, the measuring instrument was reliable and valid.

\section{RESULTS: DESCRIPTIVE STATISTICS}

The data collection revealed that more than half of the respondents were male $(54 \%)$, and the majority of the respondents $(84 \%)$ were between the ages of 18 and 44 years.

Of the 379 respondents, $31 \%$ originated from African countries, $26 \%$ originated from American countries, $14 \%$ originated from European countries, $2 \%$ originated from North America, $1 \%$ originated from Australasia, and $25 \%$ originated from other countries, which were predominantly locations in Southern Asia, including Pakistan, Sri Lanka, Malaysia, India, Bangladesh, Philippines, Vietnam, and Indonesia.

According to the data collected, $25 \%$ of the respondents worked and resided in Beijing, $24 \%$ in Shanghai, $8 \%$ in Shenzhen, $6 \%$ in Guangzhou, 6\% in Xi'an, 4\% in Hangzhou, 3\% in Nanjing, 3\% in Chengdu and 2\% in Ningbo. The remaining 19\% of respondents indicated that they worked and resided in other locations, which included Asian cities and remote or online teaching.

A large proportion of the respondents (35\%) had 1 year or less experience as a TEFL teacher, $32 \%$ had 2 years' experience, $17 \%$ had 3 years' experience, $9 \%$ had 5 years' or more experience and $7 \%$ had 4 years' experience. Furthermore, $54 \%$ of the respondents held a bachelor's degree, $19 \%$ held a master's degree, $10 \%$ held a high school education, $8 \%$ had either a trade/vocational or technical education, $4 \%$ held a college degree, $3 \%$ had other forms of tertiary education and $2 \%$ had a national diploma. 
Finally, the majority of the respondents (78\%) indicated that they had a 120 -hour TEFL certificate and $10 \%$ indicated that they did not possess any form of TEFL teaching certificate. The remaining $12 \%$ indicated that they had another type of teaching certificate, such as a PGCE 100-hour TEFL certificate, a 150-hour CELTA certificate, or a 168-hour TEFL certificate. Lastly, 83\% of the respondents indicated a positive overall experience of teaching TEFL in China.

\section{RESULTS: INFERENTIAL STATISTICS}

Inferential statistics were used to test the hypotheses of the study and the correlation of the items. For the purpose of the study, Spearman's correlation coefficient was utilised to identify correlations between the variables. The correlations between the independent variables and the dependent variable as well as the sub-variables of the study are presented in Table 1 below.

From Table 1, it can be seen that a strong correlation of 0.51 existed between social influences and overall experience as well

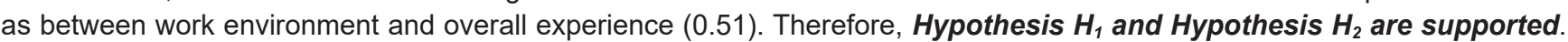
Additionally, the strong correlation of 0.52 that existed between the presence of an expatriate community and overall experience supports $\boldsymbol{H y p o t h e s i s} \boldsymbol{H}_{1 a}$. The moderate correlations that existed between the presence of a language barrier (0.39), access to healthcare (0.37), and overall experience also support Hypotheses $\boldsymbol{H}_{1 b}$ and $\boldsymbol{H}_{1 d}$. However, Hypothesis $\boldsymbol{H}_{1 c}$ is rejected because of the weak correlation that existed between overall experience and acceptance by locals $(0.18)$. Finally, $\boldsymbol{H y p o t h e s e s}$ $\boldsymbol{H}_{2 a}$ and $\boldsymbol{H}_{2 b}$ are supported by the moderate correlations that existed between work conditions (0.45), working hours (0.47), and overall experience.

For the purpose of the study, a primary and secondary factor ordinal logistic regression was run to determine the effect of several positive and negative affectivity factors on the overall experience of foreign TEFL teachers in China. Table 2 presents the model fitting information for the primary factor ordinal regression conducted.

The final model was found to predict statistically and significantly the dependent variable above the intercept-only model, $\chi^{2}(6)=137.73, p<0.00$. The significant predictor was social influences, which had an influence on the overall experience of teaching TEFL in China. This is seen in Table 3, which presents the tests of model effects and parameter estimates.

Table 3 shows that an increase in the social influences factor score was associated with an increase in the odds of the respondents' overall experience being high (positive/very positive), with an odds ratio of $2.80(95 \% \mathrm{Cl}, 1.10$ to 7.14$), \chi^{2}(1)=4.65, \mathrm{p}=0.03$. Therefore, respondents with higher social influences factor scores were 2.80 times more likely to have a more positive overall experience. Table 4 presents the model fitting information for the secondary factor ordinal regression conducted.

The final model was found to predict statistically and significantly the dependent variable above the intercept-only model, $\chi^{2}(11)=152.82, p<0.00$. The significant predictor was the presence of an expatriate community, as seen in Table 5 , which presents the tests of model effects and parameter estimates.

Table 1: Correlations between the variables of the study

\begin{tabular}{|c|c|c|c|c|c|c|c|c|c|}
\hline Variable & 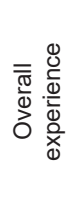 & 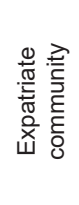 & 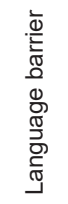 & 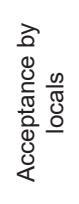 & 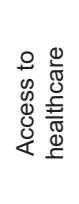 & 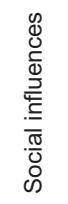 & 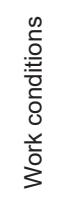 & 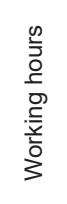 & 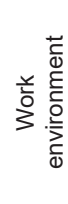 \\
\hline Overall experience & 1.00 & $.52^{\star}$ & $.39^{*}$ & $.18^{*}$ & $.37^{\star}$ & $.51^{\star}$ & $.45^{*}$ & $.47^{*}$ & $.51^{*}$ \\
\hline Expatriate community & & 1.00 & $.43^{*}$ & $.18^{*}$ & $.49^{*}$ & $.73^{*}$ & $.50^{*}$ & $.50^{*}$ & $.55^{*}$ \\
\hline Language barrier & & & 1.00 & $.26^{*}$ & $.56^{*}$ & $.83^{*}$ & $.48^{*}$ & $.43^{*}$ & .50 \\
\hline Acceptance by locals & & & & 1.00 & $.24^{*}$ & $.50^{*}$ & $.28^{*}$ & $.23^{*}$ & $.29^{*}$ \\
\hline Access to healthcare & & & & & 1.00 & $.77^{*}$ & $.52^{*}$ & $.51^{*}$ & $.55^{*}$ \\
\hline Social influences & & & & & & 1.00 & $.62^{*}$ & $.57^{\star}$ & $.65^{*}$ \\
\hline Work conditions & & & & & & & 1.00 & $.63^{*}$ & $.88^{*}$ \\
\hline Working hours & & & & & & & & 1.00 & $.91^{*}$ \\
\hline Work environment & & & & & & & & & 1.00 \\
\hline $\begin{array}{l}\text { * Correlation is significa } \\
\text { For practical significand }\end{array}$ & efficien & $<0.30:$ & corre & $n, 0.30$ & : Mode & orrel & $0.50+$ & $\mathrm{g} \mathrm{cc}$ & \\
\hline
\end{tabular}

Source: Authors' own description, based on research results. 
Table 2: Model fit information for the primary factor ordinal regression conducted

\begin{tabular}{|c|c|c|c|c|}
\hline \multicolumn{5}{|c|}{ Model Fitting Information } \\
\hline Model & -2 Log Likelihood & Chi-Square & df & Sig. \\
\hline Intercept only & 420.24 & & & \\
\hline Final & 282.51 & 137.73 & 6 & $0.00^{*}$ \\
\hline
\end{tabular}

Source: Authors' own description, based on research results.

From Table 5, it can be concluded that an increase in the expatriate community factor score was associated with an increase in the odds of the respondents' overall experience being high (positive/very positive), with an odds ratio of 2.26 ( $95 \% \mathrm{Cl}, 1.21$ to 4.20$) \cdot \chi^{2}(11)=6.58, p=0.01$. Therefore, respondents with higher expatriate community factor scores were 2.26 times more likely to have a higher, or more positive, overall experience.

\section{DISCUSSION}

With reference to the presence of an expatriate community, it can be concluded that TEFL teachers who teach in China can benefit from interacting with people who are sharing a similar experience as themselves. This affirms the opinions of Schmidt (2019) and Van der Laken et al. (2019) who explain that the presence of an expatriate community makes the transition into a new country easier, as expatriates are able to form social bonds with others in a similar situation (DeVries, 2017). Furthermore, it can be deduced that interaction with other expatriates may be linked to a deeper level of connection with other individuals.

The findings of the study relating to the potential influence of a language barrier revealed that the respondents in general felt that a language barrier did not have a negative influence on their overall experience of TEFL in China. Furthermore, while the dialect of spoken English may differ between host nationals and foreign TEFL teachers, respectful, two-way communication is still possible. This was revealed by the finding that more than half of the respondents indicated that their experience was positively influenced by the level of respect shown toward them by Chinese host nationals, even if they were unable to speak the home language of the country.

Another conclusion drawn from this study is that the attitudes of locals toward foreign TEFL teachers, both inside and outside the workplace, as well as socialising with locals, generally had a positive influence on the TEFL teachers' overall experience in China. These findings strengthen the claims of Sokro and Pillay (2020), Mahajan and Toh (2014), and Carneiro and Eusébio (2015), who note that interaction between locals and expatriates can have a positive impact on their overall experience.

The findings revealed that the respondents felt that healthcare factors had a positive influence on their overall experience. Access to healthcare, standards of healthcare facilities, and the quality of care provided by healthcare specialists in China

Table 3: Tests of model effects and parameter estimates for the primary factors

\begin{tabular}{|c|c|c|c|c|c|c|c|c|c|}
\hline \multicolumn{10}{|c|}{ Parameter Estimates } \\
\hline & \multirow{2}{*}{ Parameter } & \multirow{2}{*}{ B } & \multirow{2}{*}{$\begin{array}{l}\text { Std. Error } \\
\text { Wald Chi- } \\
\text { Square }\end{array}$} & \multicolumn{3}{|c|}{ Hypothesis Test } & \multirow{2}{*}{$\begin{array}{c}\text { Exp(B) } \\
\text { - Odds } \\
\text { Ratio } \\
\text { Lower }\end{array}$} & \multicolumn{2}{|c|}{$\begin{array}{l}95 \% \text { Wald Confidence } \\
\text { Interval for } \operatorname{Exp}(B)\end{array}$} \\
\hline & & & & df & $\begin{array}{l}\text { Sig. } \\
(p<.05)\end{array}$ & & & Upper & \\
\hline \multirow{2}{*}{ Threshold } & [Overall experience $=1.00$ ] & 9.88 & 1.44 & 47.30 & 1 & 0.00 & 19552 & 1170.20 & 326691.69 \\
\hline & [Overall experience $=2.00$ ] & 12.04 & 1.52 & 62.58 & 1 & 0.00 & 168585 & 8546.20 & 3325553.00 \\
\hline \multicolumn{2}{|c|}{ Social influences } & 1.0 & 0.48 & 4.65 & 1 & $0.03^{*}$ & 2.80 & 1.10 & 7.14 \\
\hline \multicolumn{2}{|c|}{ Work environment } & 0.08 & 0.37 & 0.04 & 1 & 0.84 & 1.08 & 0.52 & 2.25 \\
\hline \multicolumn{2}{|l|}{ (Scale) } & $1 \mathrm{a}$ & & & & & & & \\
\hline
\end{tabular}

Dependent variable: Overall experience

Model: (threshold), social influences, work environment

Fixed at the displayed value

Marked effects $\left({ }^{*}\right)$ are significant at $p<.05$

Source: Authors' own description, based on research results. 
Table 4: Tests of model effects and parameter estimates for the primary factors

\begin{tabular}{lcccc}
\hline \multicolumn{1}{c}{ Model } & Model Fitting Information & & df & Sig. \\
\hline Intercept only & $\mathbf{- 2}$ Log Likelihood & Chi-Square & & 11 \\
Final & 420.24 & & & $0.00^{*}$ \\
\hline Link function: Logit & 267.42 & & & \\
Marked effects $\left(^{*}\right)$ are significant at $p<.05$ & & & & \\
\hline
\end{tabular}

Source: Authors' own description, based on research results.

were satisfactory according to the study results. These findings support Moopen (2020), who claims that ideally, healthcare should be accessible, affordable, and of an acceptable quality to have a positive impact on an individual's well-being. Finally, the conclusion was drawn that access to healthcare was facilitated by health insurance provided by the respondents' employers and social services, which confirms the earlier statement that employers often include medical insurance in contracts signed with expatriates (Deady, 2018).

Concerning the overall working conditions of TEFL teachers in China, the findings revealed that they are reasonably good, based on the fact that the majority of the respondents indicated that their physical work environment positively influenced their overall experience as TEFL teachers in China. This finding lends support to Kitila (2017) as well as Oludeyi (2015), who maintain that an individual's work environment can influence his/her satisfaction. Furthermore, the study revealed that TEFL teachers in China are treated well and fairly in the workplace by their employers, affirming the claim by Isaacs (2020), who notes that teachers' roles/responsibilities and performance standards in Chinese private schools differ from those in public schools. Finally, with reference to the specific working hours of TEFL teachers, respondents felt that the factors constituting this variable positively influenced their overall experience. Respondents reported that their total working hours and the balance between work and private time positively influenced their overall experience, leading to the conclusion that TEFL teachers live a balanced lifestyle and work schedule.

Table 5: Tests of model effects and parameter estimates for the secondary factors

\begin{tabular}{|c|c|c|c|c|c|c|c|c|}
\hline \multicolumn{9}{|c|}{ Parameter Estimates } \\
\hline \multirow{2}{*}{ Parameter } & \multirow{2}{*}{ B } & \multirow{2}{*}{$\begin{array}{l}\text { Std. Error } \\
\text { Wald Chi- } \\
\text { Square }\end{array}$} & \multicolumn{3}{|c|}{ Hypothesis Test } & \multirow{2}{*}{$\begin{array}{l}\text { Exp(B) } \\
\text { - Odds } \\
\text { Ratio } \\
\text { Lower }\end{array}$} & \multicolumn{2}{|c|}{$\begin{array}{l}95 \% \text { Wald Confidence } \\
\text { Interval for } \operatorname{Exp}(B)\end{array}$} \\
\hline & & & df & Sig. & & & Upper & \\
\hline [Overall experience $=1.00$ ] & 10.81 & 1.58 & 46.61 & 1 & 0.00 & & 2224.60 & 1104698.20 \\
\hline [Overall experience=2.00] & 13.05 & 1.68 & 60.60 & 1 & 0.00 & 463320.00 & 17351.00 & 12372093.26 \\
\hline The presence of an expatriate community & 0.81 & 0.32 & 6.58 & 1 & $0.01^{*}$ & 2.26 & 1.21 & 4.20 \\
\hline The potential influence of a language barrier & 0.57 & 0.36 & 2.43 & 1 & 0.12 & 1.76 & 0.87 & 3.58 \\
\hline Acceptance by locals & -0.00 & 0.24 & 0.00 & 1 & 0.99 & 1.00 & 0.62 & 1.59 \\
\hline Access to healthcare & -0.50 & 0.30 & 2.83 & 1 & 0.09 & 0.61 & 0.34 & 1.09 \\
\hline Working hours & -0.06 & 0.35 & 0.03 & 1 & 0.87 & 0.94 & 0.47 & 1.89 \\
\hline Work conditions & 0.24 & 0.39 & 0.36 & 1 & 0.55 & 1.27 & 0.59 & 2.75 \\
\hline (Scale) & $1 \mathrm{a}$ & & & & & & & \\
\hline \multicolumn{9}{|l|}{ Dependent Variable: Overall experience } \\
\hline \multicolumn{9}{|c|}{ Model: (threshold), expatriate community, language barrier, acceptance by locals, access to healthcare, working hours, work conditions } \\
\hline \multicolumn{9}{|l|}{$\begin{array}{l}\text { Fixed at the displayed value } \\
\text { Marked effects }\left(^{*}\right) \text { are significant at } p<.05\end{array}$} \\
\hline
\end{tabular}

Source: Authors' own description based on research results. 


\section{CONCLUSIONS}

The study revealed that the presence of an expatriate community ensures the expatriate TEFL teachers' smooth transition into China. Therefore, institutions hiring TEFL teachers should build such a community by encouraging team-building or other employee-centric activities amongst staff members. Additionally, institutions should provide expatriate TEFL teachers with a list of recommended expatriate sites on social media platforms where they could meet with other expatriates. Moreover, the potential TEFL teacher should proactively network with current teachers prior to arriving in the country. This could be done by joining online social media platforms designed specifically for expatriate TEFL teachers to connect with one another; examples can be found on Facebook, WeChat, Linkedln, or Reddit.

With reference to the challenge of a language barrier, institutions should make sure that the contracts they offer TEFL teachers include language lessons in the home language of the relevant country, such as Chinese or Mandarin. Furthermore, adjustment should be made to policies so that English is the recognised business language of the school, which will encourage host nationals to communicate with each other and the expatriate co-workers in English, thereby minimising the language barrier in the workplace. In addition, since most apps from outside the country do not work in China, it may be helpful for institutions to recommend a Chinese mobile app (Zeng, 2020) that the TEFL teacher can download on arrival to facilitate the translation of words, phrases, and sentences, with the app acting as a translator. Another recommendation is that potential TEFL teachers invest in learning the basics of the language before arriving in China, so they can begin to communicate right away.

To facilitate acceptance by locals, it is recommended that institutions who hire TEFL teachers create an inclusive organisational culture to ensure that all staff members operate as a team, rather than accomplishing tasks independently. In addition, institutions should provide mentoring to their expatriate TEFL teachers, both on arrival in the form of an "orientation week" as well as continuously throughout their employment regarding acceptable interactional behavior in the country. Potential TEFL teachers should take the time to research the country and region's culture, social behaviour/norms, communication, traditions, mannerisms, and customs prior to arrival. Moreover, once in the country, TEFL teachers should try to build relationships with locals, which will provide the opportunity to learn more about their way of life. Finally, TEFL teachers should remember that they are in the local people's home country, and they need to be respectful of them, instead of imposing their own behavior on host nationals.

Concerning access to healthcare, to accommodate expatriate TEFL teachers, institutions should include medical insurance in their contracts. In addition, especially with regard to the current global COVID-19 pandemic, institutions should make provision for expatriate TEFL teachers to remain safe by following protocol and encouraging employees to report any symptoms. Potential TEFL teachers must thoroughly check their contracts to establish whether their employers provide medical insurance; and if not, the applicant should query this, as medical insurance in most cases is a non-monetary benefit associated with teaching TEFL in China. In addition, TEFL teachers should confirm the terms of the medical insurance provided, as in some cases the employer may stipulate that they will take a contribution from the TEFL teacher's salary every month. If a TEFL teacher's employer does not provide medical insurance, it is recommended that the teacher individually research healthcare packages, as medical treatment is expensive in China.

Regarding work conditions, it is recommended that institutions who hire TEFL teachers form an ideal image of the type of TEFL teacher they would like to employ and ensure that they portray this in their advertisements to attract suitable TEFL teachers. Furthermore, institutions should be specific in the wording of their advertisements to ensure that they only receive applications from teachers who could potentially be a good fit with their school. Finally, institutions must be careful not to boast only about the benefits for applicants, as this might attract TEFL teachers whose motives are purely financial. The institutions also need to be clear about specific job responsibilities and performance standard expectations. Potential TEFL teachers should conduct extensive research on the differences between private and public schools prior to applying for a position at either. Once applicants have decided which environment will best suit them, they need to ensure that they are qualified for the post, as each type of school has different requirements for employment. Should it be the TEFL teachers' first time teaching at a private or public school, it is also recommended that they ensure that their contract provides the option to give notice to leave a position, which will give them freedom to change should the environment be unsuitable.

With respect to specific working hours, institutions hiring TEFL teachers should consider all aspects that contribute toward a balanced life for their employees and then try to provide these, without sacrificing working hours. This can be done by conducting internal research and collecting data from their employees, which will make it possible to highlight the aspects that the employees consider most important. Potential TEFL teachers must conduct extensive research on the normal working hours expected of them and then compare these to those quoted in their employment contract. It is also advisable for TEFL teachers to have the employer specify a breakdown of exactly how their working hours will be allocated. Finally, as many 
employment contracts contain a clause concerning overtime pay, it is recommended that all TEFL teachers keep a record of the hours they work in a month to ensure they are being compensated accordingly.

Future research should be conducted on the experience of TEFL teaching in China from the perspective of educational institutions, on the one hand, and of host nationals, on the other. In addition, due to the effects of the COVID-19 pandemic, it would be of interest to reconduct the research study described in this article when pandemic restrictions are over to compare what variables TEFL teachers in China identify as having a significant influence on their overall experience following the pandemic. Alternatively, a study could be done to establish, from the respondents' perspective, the degree to which the pandemic has affected their experiences and modified their previous opinions of TEFL in China.

\section{ACKNOWLEDGMENTS}

I should like to offer a sincere thank you to all the people who contributed to the completion of my study, in one way or another. Special thanks are extended to the following individuals:

- Dr. A. Potgieter for her guidance, continued support, mentorship, and words of encouragement throughout the study.

- To my friends and family for their encouragement and support to ensure the successful completion of the study.

- Ms. C. Stindt from the NMU statistical unit for her specialised support and assistance with data processing and analysis

- Ms. R. Ferreira for the language editing.

- The respondents, the TEFL teachers, for their willingness to participate in the study and for their cooperation.

\section{References}

Agboza, G. K., Owusu, I. S., Hoedoafia, M. A., \& Atakorah, Y. B. (2017). The effect of work environment on job satisfaction: Evidence from the banking sector in Ghana. Journal of Human Resource Management, 5(1), 12-18. http://article.sciencepublishinggroup.com/html/10.11648.j.j hrm.20170501.12.html

Bonache, J., Brewster, C., Suutari, V., \& Cerdin, J. L. (2017). The changing nature of expatriation. Thunderbird International Business Review, 60(6), 815-821. https://doi.org/10.1002/tie.21957

Carneiro, M. J., \& Eusébio, C. (2015). Host-tourist interaction and impact of tourism on residents' quality of life. Tourism and Management Studies, 11(1), 25-34.

Ching, Y., Renes, S. L., McMurrow, S., Simpson, J., \& Strange, A. T. (2017). Challenges facing Chinese international students studying in the United States. Educational Research and Reviews, 12(8), 473-482. https://files.eric.ed.gov/fulltext/EJ1139861.pdf

Chiona, V. (2017). How to deal with language barriers as an expat. I am Expat. https://www.iamexpat.nl/expat-info/dutch-expat-news/how-deallanguage-barriers-expat

Collewet, M., \& Sauermann, J. (2017). Working hours and productivity. Institute of Labour Economics, Discussion Paper Series: 1-35. https:// ideas.repec.org/p/iza/izadps/dp10722.html

Costa, E. (2018, October 22). Mandarin's rise to prominence and why you should pick it up. Study International. https://www.studyinternational. com/news/if-you-want-to-succeed-learn-mandarin/

Deady, K. (2018, September 28). What's the average salary for a teacher in China? Teach Away. https://www.teachaway.com/blog/whats-averagesalary-teacher-china

DeVries, M. M. (2017). Integration, mobility and connection: An anthropological study of expat communities in the Netherlands [Unpublished master's dissertation]. Utrecht University.

Drucker, P. F. (2017, March 28). 8 cultural differences in nonverbal communication. Point Park University. https://online.pointpark.edu/business/ cultural-differences-in-nonverbal-communication/

Fisher, M. (2013, March 21). A surprising map of the countries that are most and least welcoming of foreigners. The Washington Post. https://www. washingtonpost.com/news/worldviews/wp/2013/03/21/a-fascinating-map-of-countries-color-coded-by-their-openness-to-foreigners/

Foundation Health Measure Report. (2020). Health-related quality of life and well-being. ODPHP. https://www.healthypeople.gov/2020/about/ foundation-health-measures/Health-Related-Quality-of-Life-and-Well-Being

Galloway, L. (2019, August 19). What's it like to live in an over-touristed city? BBC Travel. http://www.bbc.com/travel/story/20190818-whats-it-liketo-live-in-an-over-touristed-city 
Geher, G. G., Levoy, G., Smillie, L., \& Caputi, T. L. (2020). Social life. Psychology Today. https://www.psychologytoday.com/za/basics/social-life

Globalization Partners International (GPI). (2016). Cultural, political and social factors influence the meaning of translations. GPI. https://www. globalizationpartners.com/2016/06/09/cultural-political-and-social-factors-influence-the-meaning-of-translations/

Grossberg, B. (2019, November 10). 5 differences between public and private schools. ThoughtCo. https://www.thoughtco.com/major-differencesbetween-public-and-private-2773898

Guettou, I. (2018, April 9). Developed vs developing countries: What's the impact on healthcare coverage? PR Newswire. https://www.prnewswire. com/news-releases/developed-vs-developing-countries-whats-the-impact-on-healthcare-coverage-300626432.html

Hello Teacher. (2020). Teaching in China 2020: Essential information. Hello Teacher. https://www.helloteacher.asia/info/category/teaching-in-china Holland, J. (2019, December 2). What is an expat? International Living. https://internationalliving.com/what-is-an-expat-qa/

Hunt, E. (2018, July 17). Residents in tourism hotspots have had enough. So, what's the answer? The Guardian. https://www.theguardian.com/ cities/2018/jul/17/residents-in-tourism-hotspots-have-had-enough-so-whats-the-answer

i-to-i. 2020. What qualifications do I need to teach English abroad? https://www.i-to-i.com/tefl-faq/what-qualifications-do-i-need-to-teach-englishabroad/

International Labour Organization. (2020). ILO: As job losses escalate, nearly half of global workforce at risk of losing livelihoods. International Labour Organization. https://www.ilo.org/global/about-the-ilo/newsroom/news/WCMS_743036/lang--en/index.htm

The International TEFL Academy. (2020). Are there age limits or restrictions to teach English abroad? International TEFL Academy. https://www. internationalteflacademy.com/blog/age-limits-for-teach-english-abroad

InterNations. (2020). What's an expat anyway? https://www.internations.org/guide/global/what-s-an-expat-anyway-15272

Isaacs, B. (2020). Schools: Public vs private. Independent Online (IOL). https://www.iol.co.za/capeargus/opinion/schools-public-vs-private-43876884

Jokhio, A. A., Raza, S. S., Younus, M., \& Soomro, A. H. (2020). Teaching writing skills in university large classes in Pakistan: Issues, challenges and solutions. Journal of English Education and Linguistics Studies, 7(1), 25-47. https://www.researchgate.net/publication/340828184_TEACHING_WRITING_SKILLS_IN_UNIVERSITY_LARGE_CLASSES_IN_PAKISTAN_ISSUES_CHALLENGES_AND_SOLUTIONS

Kaiser, H.F. (1960). The application of electronic computers to factor analysis. Educational and Psychological Measurement, 20(1), 141-151. https://doi.org/10.1177\%2F001316446002000116

Kelly, M. (2019). Public vs. private school teaching. ThoughtCo. https://www.thoughtco.com/teaching-at-private-vs-public-schools-7937

King, J. (2018, August 22). My experience of teaching English in China at first leap in Beijing. China TEFLer. https://www.chinatefler.com/teflschools-and-reviews/my-experience-teaching-english-in-china-at-first-leap-in-beijing/

Kitila, E. T. (2017). Effects of workplace environment on worker's performance and productivity in Tanzania: A case of selected micro and small enterprises (SMME's) in Dar Es Salaam [Unpublished master's dissertation]. Mzumbe University.

Kolakowski, S. (2018, April 23). Here's when it gets more difficult to learn a new language, according to science. Insider. https://www.businessinsider.com/learn-a-new-language-2018-4?IR=T

Kuo, L., \& Davidson, H. (2020, March 29). They see my blue eyes then jump back: China sees a new wave of xenophobia. The Guardian. https:// www.theguardian.com/world/2020/mar/29/china-coronavirus-anti-foreigner-feeling-imported-cases

Lee, D., \& Lim, H. (2017). Multiple thresholds in the nexus between working hours and productivity. Contemporary Economic Policy, 35(4), 716-734. https://doi.org/10.1111/coep.12230

Mahajan, A., \& Toh, S. (2014). Facilitating expatriate adjustment: The role of advice-seeking from host country nationals. Journal of World Business, 49(4), 476-487. https://doi.org/10.1016/j.jwb.2013.10.003

Makovsky, K. (2014, April 3). Communicating in different countries. Forbes. https://www.forbes.com/sites/kenmakovsky/2014/04/03/communicating-in-different-countries/\#4f79fd6a782a

Masenya, M. J. (2017). Afrophobia in South Africa: A general perspective of xenophobia. Bangladesh e-Journal of Sociology, 14(1), 81-88. https:// doi.org/10.1080/23311983.2020.1859074

Massey, J. (2016). 21 ${ }^{\text {st }}$ century expatriates. International Journal of Management and Applied Science, 2(12), $155-161$.

Mathis, W. J. (2017). The effectiveness of class size reduction. Psychosociological Issues in Human Resource Management, 5(1), 176-183. https://nepc.colorado.edu/sites/default/files/publications/Mathis\%20RBOPM-9\%20Class\%20Size.pdf

Maxwell, D. (2019). Precarious times for TEFL teachers in China. Study International. https://www.studyinternational.com/news/precarious-timesforeign-teachers-china/

Mayes-Tang, S. (2017, November 28). The challenges of teaching large classes, part 1: Active learning. Medium. https://medium.com/@SMayesTang/the-challenges-of-teaching-large-classes-part-1-active-learning-c0d0ec2bac7

McNulty, Y., \& Brewster, C. (2017a). The concept of business expatriates. In Y. McNulty \& J. Selmer, (Eds.), Research Handbook of Expatriates (pp. 1-39). UK: Edward Elgar. 
McNulty, Y., \& Brewster, C. (2017b). Theorizing the meaning(s) of expatriate: Establishing boundary conditions for business expatriates. The International Journal of Human Resource Management, 1(Annual Review), 27-61. https://www.tandfonline.com/doi/abs/10.1080/09585192.2 016.1243567

Meador, D. (2019, July 3). What is the difference between teaching in public vs. private schools? ThoughtCo. https://www.thoughtco.com/teachingin-public-vs-private-schools-3194634

Mitchell, D. (2019, March 31). Teaching English in China salary: How much can you make in 2020? Work and Live in China. https://www.workandliveinchina.com/teaching-english-in-china-salary/

Mogawakwe, L. J., Ally, H., \& Magobe, N. B. D. (2020). Reasons for non-compliance with quality standards at primary healthcare clinics in Ekurhuleni, South Africa. African Journal of Primary Health Care \& Family Medicine, 12(1), 2071-2928. http://dx.doi.org/10.4102/phcfm.v12i1.2179

Moopen, A. (2020, April 15). The importance of accessible and sustainable healthcare. Omnia Health. https://insights.omnia-health.com/hospitalmanagement/importance-accessible-and-sustainable-healthcare

Mueller, S. (2013). Teacher experience and the class size effect: Experimental evidence. Journal of Public Economics, 98(C), 44-52. https:// econpapers.repec.org/article/eeepubeco/v_3a98_3ay_3a2013_3ai_3ac_3ap_3a44-52.htm

Nunnally, J.C. (1978). Psychometric theory. $2^{\text {nd }}$ ed. New York: McGraw-Hill.

Nunnally, J. C., \& Bernstein, I. H. (1994). Psychometric theory. McGraw-Hill.

Okazaki, E., Nishi, D., Susukida, R., Inoue, A., Shimazu, A., \& Tsutsumi, A. (2018). Association between working hours, work engagement, and work productivity in employees: A cross-sectional study of the Japanese study of health, occupation, and psychosocial factors relates equity. Journal of Occupational Health, 61(2), 182-188. https://www.researchgate.net/publication/331291473_Association_between_working_hours_work_engagement_and_work_productivity_in_employees_A_cross-sectional_study_of_the_Japanese_Study_of_Health_Occupation_and_Psychosocial_Factors_Relates_Equity

Okulicz-Kozaryn, A., \& Strzelecka, M. (2017). Happy tourists, unhappy locals. Social Indicators Research, 234(2), 789-804. https://ideas.repec. org/a/spr/soinre/v134y2017i2d10.1007_s11205-016-1436-9.html

Oludeyi, O. S. (2015). A review of literature on workplace environment and work commitment: Implication for future research in citadels of learning Journal of Human Resource Management, 18(2), 33-46.

Opportunity China. (2017). Types of school in China: What are the differences, and what type would be a good fit for me? https://www.opportunitychina.com/blog/types-of-school-in-china-differences-blog/

Opportunity China. (2020). Teacher experiences. https://www.opportunity-china.com/go-teach-in-china/teacher-experiences/

Osborne, H. (2020, April 21). Why the COVID-19 death forecasts are wrong. Newsweek. https://www.newsweek.com/why-covid-19-death-forecasts-are-wrong-1499243

Palmer, Maggie. Bridge TEFL. (2020, March 5). Teaching English online vs. the classroom: How do they compare? Global ELT News, Bridge Universe. https://bridge.edu/tefl/blog/teaching-online-vs-classroom/

Pogosyan, M. (2017, June 29). Non-verbal communication across cultures: When our gestures speak louder than our words. Psychology Today. https://www.psychologytoday.com/za/blog/between-cultures/201706/non-verbal-communication-across-cultures

Quinn, C. (2019, September 19). The country where over 260k ESL work illegally. The Pie News. https://thepienews.com/analysis/china-eslteachers-work-illegally/

Rani, K. U. (2016). Communication barriers. Journal of English Language and Literature, 3(2), 74-76.

Reach to Teach. (2020). Requirements to teach in China. Retrieved from: https://www.reachtoteachrecruiting.com/teach-english-in-china.html

Ročkè, D. (2017, May 12-13). Expatriation: Challenges and success factors of an international career [Conference presentation]. Latvia University of Agriculture. https://agris.fao.org/agris-search/search.do?recordID=LV2017000359

Rousseau, S. (2020). The importance of celebrating your traditions as an expat. InterNations. https://www.internations.org/magazine/observingholidays-and-traditions-abroad-16216/the-importance-of-celebrating-your-traditions-as-an-expat-2

Schmidt, D. (2019). 7 ways to adjust to a new country, culture when moving overseas. The Spruce. https://www.thespruce.com/effects-of-movingto-a-new-country-2436102

Settersten, R. A., \& Thogmartin, A. (2018). Flux: Insights into the social aspects of life transitions. Research in Human Development, 15(3-4), 360-373. https://doi.org/10.1080/15427609.2018.1513779

Skrybus, Elwira. (2018, September 24). What is the cost of health insurance in China in 2018. Pacific Prime China. http://pacificprime.cn/blog/ what-is-the-cost-of-health-insurance-in-china-in-2018/

Sokro, E., \& Pillay, S. (2020). Host country nationals' attitude, social support and willingness to work with expatriates. Global Business Review, 21(5), 1184-1199. https://doi.org/10.1177/0972150919857012

Soler, J., \& Marten, H. F. (2019). Resistance and adaptation to new speakerness in educational institutions: Two tales from Estonia. Language Policy, 18, 553-572. https://doi.org/10.1007/s10993-018-9497-z 
Solomon, C. (2019, June 7). The expat adjustment cycle: How to minimize culture shock. Culture Wizard. https://www.rw-3.com/blog/the-expatadjustment-cycle-how-to-minimize-culture-shock

Spasojevic, N., Vasilj, I., Hrabac, B., \& Celik, D. (2015). Rural - urban difference in healthcare quality assessment. Journal of the Academy of Medical Sciences of Bosnia and Herzegovina, 27(6), 409-411. https://www.ncbi.nlm.nih.gov/pmc/articles/PMC4753384/

Taleb-Agha, R. (2020, May 29). What are the requirements to teach English abroad? Go Overseas. https://www.gooverseas.com/blog/teachingenglish-abroad-requirements

The TEFL Academy. (2020). How is the TEFL market? The TEFL Academy. https://www.theteflacademy.com/tefl-learning-centre/tefl-basics/howbig-tefl-market

Tenzer, H., \& Schuster, T. (2017). Language barriers in different forms of international assignments. In Bader, B., Schuster, T. \& Bader, A (Eds.), Expatriate Management (pp. 63-100). Palgrave Macmillan.

Tingley, S. C. (2020). Teaching at a private school: Pros and cons. Hey Teach! Western Governors University. https://www.wgu.edu/heyteach/ article/teaching-private-school-pros-and-cons1701.html

Van der Laken, P. A., Engen, M. L., Veldhoven, M. J. P. M., \& Paauwe, J. (2019). Fostering expatriate success: A meta-analysis of the differential benefits of social support. Human Resource Management Review, 29(4), 1-22. https://doi.org/10.1016/j.hrmr.2018.12.003

Wang Ying, X. (2017, June 3). Popularity of Chinese language learning soaring within U.S education system: survey. New China. http://www. xinhuanet.com//english/2017-06/03/c_136336004.htm

Yim, S. Y., \& Ahn, T. Y. (2018). Teaching English in a foreign country: Legitimate peripheral participation of a native English-speaking teacher. System, 78, 213-223. https://doi.org/10.1016/j.system.2018.09.008

York, J. (2019, November 26). Is it safe to teach English in China? Yes, of course! Teach Away. https://www.teachaway.com/blog/teach-englishin-china-safety

Zafar, M., Karim, E., \& Omair, A. (2017). Factors of workplace environment that affects employee performance in an organization: A study on Greenwich University of Karachi. Munich Personal RePEc Archive. https://mpra.ub.uni-muenchen.de/78822/

Zeng, M. (2020). Keeping in touch in China. China Highlights. https://www.chinahighlights.com/travelguide/guidebook/keep-in-touch.htm

Zhang, J., Xu, H. G., \& Xing, W. (2017). The host-guest interaction in ethnic tourism, Lijiang, China. Current Issues in Tourism, 20(7), 724-739. https://doi.org/10.1080/13683500.2016.1178218

Zhang, L. E., \& Harzing, A. W. (2016). From dilemmatic struggle to legitimized indifference: Expatriates' host country language learning and its impact on the expatriate-HCE relationship. Journal of World Business, 51(5), 774-786. https://doi.org/10.1016/j.jwb.2016.06.001

Zhang, L. E., Harzing, A. W., \& Fan, S. X. (2017). Managing expatriates in China. Palgrave Macmillan. 